\title{
Influenza viremia and the potential for blood-borne transmission
}

\author{
Anna M. Likos, David J. Kelvin, Cheryl M. Cameron, Thomas Rowe, Matthew J. Kuehnert, and \\ Philip J. Norris for the National Heart, Lung, and Blood Institute Retrovirus Epidemiology Donor \\ Study-II (REDS-II)
}

I nfluenza is a major cause of morbidity and mortality in the United States and worldwide. The threat of pandemic influenza recently has gained prominent attention because of widespread infection of poultry with highly pathogenic avian influenza A (H5N1) and the potential for the virus to mutate into one capable of efficient human-to-human transmission. As of March 8, 2007, 277 human cases of H5N1 infection had been reported to WHO from Asia, ${ }^{1,2}$ Eastern Europe, ${ }^{3,4}$ and Africa, ${ }^{3}$ mostly as a result of close contact between humans and infected birds, although rare, unsustained human-to-human transmission has been documented. If a change in viral characteristics were to allow efficient human-to-human transmission, rapid spread and a worldwide pandemic could result. The global spread of H5N1, continuing outbreaks in birds, and sporadic infections in humans have increased concern that a pandemic virus may emerge and cause an influenza pandemic. The possibility of an

ABBREVIATION: CSF = cerebrospinal fluid.

From the Centers for Disease Control and Prevention, Atlanta, Georgia; the University Health Network, Toronto, Ontario, Canada; the Southern Research Institute, Birmingham, Alabama; Blood Systems Research Institute, San Francisco, California; and the Departments of Laboratory Medicine and Medicine, University of California at San Francisco, San Francisco, California.

Address reprint requests to: Philip J. Norris, MD, Blood Systems Research Institute, 270 Masonic Avenue, San Francisco, CA 94118; E-mail: pnorris@bloodsystems.org.

Sponsored by REDS II, NIH Contract N01 HB57181, and

the Canadian Institutes of Health Research.

The findings and conclusions of this report are those of the authors and do not necessarily represent the views of the Department of Health and Human Services.

Received for publication January 29, 2007; revision received February 26, 2007, and accepted February 27, 2007.

doi: 10.1111/j.1537-2995.2007.01264.x

TRANSFUSION 2007;47:1080-1088. influenza pandemic has focused attention on the epidemiology and pathophysiology of influenza, including its potential for transmission through the blood supply.

An infectious agent which has a blood-borne phase and can be clinically asymptomatic has the potential to be transmitted by blood transfusion. Planning to ensure an adequate and safe national blood supply during a pandemic prompted consideration of the potential for transfusion-transmitted influenza. Notably, no cases of transfusion transmission of influenza have been documented to date. The risk of transfusion transmission has been assumed to be negligible based on the premise that viremia rarely occurs and does not occur without symptoms, allowing for deferral of potentially infectious blood donors. If these assumptions are incorrect, however, and influenza infection commonly involves a viremic phase, especially before the onset of symptoms, and if influenzainfected blood resulted in clinical illness, it would have implications for blood safety. To further examine this possibility, we surveyed the literature underlying these assumptions and propose methods of redressing gaps in our knowledge.

If influenza were transmissible by transfusion, blood product recipients, who include a high proportion of immunocompromised patients, might suffer increased morbidity and mortality. In bone marrow transplant populations influenza infection appears to be associated with approximately 25 percent mortality. ${ }^{5,6}$ If influenza were deemed to represent a transfusion transmission risk, possible screening methods would likely rely on epidemiologic query or laboratory screening. With any screening there is a risk of impacting supply. Testing of the blood supply would also become particularly important if a pandemic were to be caused by a virus similar to the highly pathogenic influenza A (H5N1). Infection in humans has thus far resulted in approximately 60 percent case fatality ratio where the virus has been isolated outside of the respiratory tract, a factor not typically seen with seasonal influenza infections. Detection of influenza in the blood of H5N1 infected humans and in animal studies has occurred predominantly during symptomatic periods and at high viral titers. A positive test might result in discarding 
the donated unit of blood, further endangering blood product availability at a time when donors may be scarce. Such additional sources of stress on the system would need to be taken into consideration when modeling the effect of a potential pandemic.

\section{BACKGROUND}

\section{Influenza epidemiology}

Seasonal influenza represents a significant contributor to overall mortality in the United States, particularly among those 65 years and older. The rates of illness and severe complications from seasonal influenza can vary substantially from year to year. In years of high influenza activity, weekly mortality incidence due to pneumonia and influenza can peak at more than 10 percent of all cause mortality in the United States (Fig. 1). ${ }^{7}$ During the 1990s, a mean of 36,000 influenza-related deaths occurred per year, with more than 90 percent of deaths occurring in the elderly. ${ }^{8}$ Estimates of annual influenza illness can range from 5 to 20 percent $^{9}$ with the highest incidence generally occurring in children. ${ }^{10-14}$ For example, during a 1976 outbreak of A/Victoria in the Houston area, an 18 percent attack rate was documented, with rates in preschool children estimated to be more than 30 percent. Influenza attack rates can be much higher in populations with close contact, with documented attack rates of 42 percent for the crew of a US Navy ship..$^{15}$ In contrast to seasonal influenza where higher illness rates occur in children compared to adults, illness rates are generally high across all age groups in a pandemic. While mean illness rates are 6 to 7 percent in healthy adults in seasonal influenza, during a pandemic illness rates are estimated to be approximately 30 percent. ${ }^{16-18}$

\section{Antigenic drift and shift and influenza reservoirs}

Influenza A is a single-stranded, negative-sense RNA virus, with eight genome segments, each complexed to a nucleoprotein molecule in the mature virion. Antigenically important regions of the virus include the hemagglutinin, responsible for virus binding to sialic acid on host cells, and the neuraminidase, needed to detach newly replicated virus from host cells. ${ }^{19}$ Antibody responses directed against the hemagglutinin protein can protect from influenza infection (reviewed by Potter and $\mathrm{Oxford}^{20}$ ), and antibodies against neuraminidase lessen disease severity. ${ }^{21}$ There are two main types of influenza viruses, Types A and B. Type B viruses are found predominantly in humans. Type A viruses can infect multiple species including humans, birds, horses, pigs, and dogs. The primary reservoir for Type A viruses, however, is birds. Influenza A viruses are subtyped based on their hemagglutinin and neuraminidase. Both Type $A$ and Type $B$ viruses are included in the annual vaccine and can cause influenza epidemics.

During influenza virus replication, errors can occur and lead to genetic variation. Changes made to antigenic regions such as the hemagglutinin molecule are termed antigenic drift. ${ }^{22}$ Antigenic drift allows individuals to have multiple infections with influenza viruses over their lifetime because antibody made against one influenza strain may not protect against distantly related drifted strains. Antigenic drift is an ongoing process and necessitates nearly yearly updates of the influenza virus strains included in influenza vaccines.

A more extreme version of antigenic variation in influenza viruses is antigenic shift, whereby genomic segments from different influenza virus strains reassort to create new combinations of gene segments. ${ }^{23}$ The new virus can acquire a novel hemagglutinin or neuraminidase gene from the pool of 16 hemagglutinin and 9 neuraminidase genes. ${ }^{24}$ Antigenic shift resulting in a strain capable of causing a human pandemic is a rare event. However, the two most recent influenza pandemic viruses arose through reassortment of human influenza A with avian influenza strains. Recent evidence suggests, however, that the 1918 influenza pandemic may have resulted from an avian influenza virus strain that acquired the capacity to infect humans by direct mutation rather than reassortment (Table 1). ${ }^{25} \mathrm{~A}$ number of avian influenza strains have caused isolated infections in humans, ranging from conjunctivitis to influenza like illness and even death. Examples of contemporary strains that have caused more 


\begin{tabular}{|cllc|}
\hline \multicolumn{4}{|c|}{ TABLE } \\
\hline 1. 20th century influenza A pandemics \\
\hline Year & Name & Strain & Estimated mortality \\
\hline 1918 & Spanish & H1N1 & $>20$ million \\
1957 & Asian & H2N2 & 70,000 \\
1968 & Hong Kong & H3N2 & 34,000 \\
\hline
\end{tabular}

than one human case of infection in recent years include H5N1, first reported in 1997, ${ }^{26}$ H9N2 reported in $1999,{ }^{27}$ H7N7 reported in 2003, ${ }^{28}$ and H7N3 reported in $2004 .{ }^{29}$ Of these, H5N1 represents the greatest current pandemic threat and will be discussed further below.

\section{EVIDENCE FOR INFLUENZA VIREMIA IN HUMAN INFECTION}

\section{Naturally occurring human cases of influenza viremia}

Relatively few studies have addressed the question of viremia caused by influenza infection, and most of these date back to the 1960s and 1970s. The first report of influenza viremia was made in 1963 by Naficy. ${ }^{30}$ Influenza virus, Group A, Type 2 (Asian) was isolated from blood drawn on Hospital Day 2 (5 days after onset of symptoms) from a 40-year-old physician ill with fever, headache, and malaise. This report followed previous suggestions of viremia based on isolation of influenza virus from postmortem tissue samples taken from patients who had died of Asian influenza infection. ${ }^{31}$ Subsequent to Naficy's publication, a single report in the literature describes influenza viremia in a naturally infected, asymptomatic patient. ${ }^{32}$ Samples were prospectively obtained from 29 clinically well close contacts of 21 ill patients in a Tehran prison. Of these 21 ill subjects, 12 had influenza virus isolated from their throat washes either in the original inoculation or after the first passage in 10-day-old embryonated chicken eggs. No virus was detected in the blood specimens of these patients after two blind passages. The 29 healthy close contacts were clinically observed for 6 days and evaluated by both throat washes and blood specimens. Of 5 subjects who developed positive throat swabs, 1 had virus isolated from both blood and throat specimens collected while asymptomatic. This individual developed clinical illness 12 hours after these specimens were collected. Subsequent specimens collected at 12 and 24 hours after onset of symptoms were negative. The number of subjects studied was small, and laboratory contamination cannot be definitively ruled out, but 1 of 5 subjects observed from the time of influenza exposure who later developed documented natural influenza infection exhibited transient viremia. Seventeen symptomatic subjects with throat wash specimens position for influenza had negative blood cultures for influenza.

Before the report by Naficy in 1963, Minuse and colleagues $^{33}$ examined 7 college students hospitalized for
Asian pandemic influenza in 1957. In spite of isolating virus from throat washes of 6 of these students and antibody evidence of infection in all 7 , none of the blood specimens yielded positive results, although pooling of serially collected specimens may have diluted out a single positive specimen beyond the infectious dose for the chick embryo. Naficy, Minuse and Khakpour all used clotted blood specimens. In contrast, Poliakova and coworkers $^{34}$ isolated influenza virus from hemolyzed blood of 11 of 63 patients, all of whom were described as having moderately severe illness. ${ }^{32}$ Ages of these 11 patients ranged from 9 months to 67 years, and virus was isolated most frequently on Day 3 after onset of symptoms (2 on Day 2, 5 on Day 3, 2 on Day 4, 1 on Day 5, 1 on Day 6, 1 on Day 7, and 1 on Day 13; 2 patients had virus isolated on 2 different days). Isolated case reports have demonstrated viremia in hospitalized patients either pre- or postmortem. ${ }^{35,36}$ More recently, Tsuruoka and associates $^{37}$ used reverse transcription-polymerase chain reaction (RT-PCR) to identify genomic influenza RNA in peripheral blood mononuclear cells (PBMNCs) taken from 18 children aged 1 to 14 years with positive throat swabs for influenza during the 1992 to 1993 season in Japan. Three of the 18 samples were RT-PCR positive with NP and/or HA primers (subtype H3, the contemporary circulating subtype). ${ }^{38}$ The NP gene sequence observed in 1 patient's PBMNCs was identical to that obtained from his throat swab, although the HA sequence of the other 2 isolates differed from the amplified throat nucleic acid by 3 to 9 nucleotides. This large number of nucleotide changes could signal either selection of a quasi-species of influenza virus that was not detected by culture or may represent contamination of samples. In addition, viral culture was not attempted in this study and thus did not assess presence of viable virus. During an influenza B outbreak in the 1994 to 1995 season, 5 of 17 red blood cell (RBC) and white blood cell (WBC) samples from 4 of 11 ill children yielded influenza B when cocultured with Madin-Darby canine kidney cells. ${ }^{39}$ In this study as well, the nucleotide and amino acid sequences varied substantially between viruses isolated from throat and blood specimens. A number of studies searching for influenza viremia after the onset of illness have failed to detect virus, supporting the notion that influenza viremia is at most a rare event in the postsymptomatic period and if it exists is not generally sustained for long periods. ${ }^{40-42}$

Indirect evidence of influenza viremia has been suggested by reports of viral detection (isolation or PCR) from extrapulmonary sites including autopsy specimens of heart, kidney, brain, spinal cord, spleen, and liver of a pregnant 19-year-old woman who died as a result of A2/HongKong/8/68 infection. ${ }^{43}$ Fetal heart tissue and amniotic fluid were also positive, as was the amniotic fluid of a 24-year-old woman who recovered from influenza A/Bangkok (H3N2) infection. ${ }^{44} \mathrm{~A}$ series of autopsies 
performed during the 1957 Asian pandemic also yielded positive results from spleen, lymph node, liver, kidney, heart, and tonsil. ${ }^{31,45}$ Systemic dissemination of influenza virus is suggested in influenza-associated encephalopathy, although virus isolation from either blood or cerebrospinal fluid (CSF) from patients with encephalopathy and influenza is rare. ${ }^{41,42,46,47}$ This may indicate that the presence of virus in the CSF is not required for the development of neurologic symptoms. Alternatively, viremia and possible infection of the CSF may precede the onset of encephalopathy. Influenza viremia has also been detected in a case of virus-associated myocarditis. ${ }^{48}$

\section{Viremia after experimental human influenza infection}

Experimental infection has resulted in isolation of virus from the blood of individuals infected by nasal inoculation. ${ }^{40}$ With a cell line coculture system, virus was detected in nasal secretions of 1 of 15 subjects and was not detected in any blood samples. Samples were available for retesting from 4 subjects with existing antibodies against Asian influenza, with each of the subjects showing a fourfold or greater increase in titer following challenge. With a more sensitive egg inoculation culture system viremia was seen in all four subjects tested. Viremia preceded nasopharyngeal shedding of virus by approximately 1 day. The authors reported that symptoms began on the second or third day after challenge, which was 2 days after the initial viremia and 1 day after demonstration of virus in the nasopharynx. One of these 4 patients remained asymptomatic throughout the observation period (22 days) and was viremic through Day 3. These results imply that viremia can precede nasopharyngeal shedding of virus and can occur in asymptomatic individuals. Caution in interpreting these data is urged, however, because others have noted that a much larger dose of influenza virus is required to effect infection when intranasal inoculation is used compared to an aerosol route, and other investigators using a similar virus strain and methods were not able to detect viremia in 27 experimentally infected patients. ${ }^{40,49}$

\section{Potential interaction of influenza with blood elements}

Influenza typically does not cause major hematologic abnormalities aside from occasional lymphopenia, usually in the setting of a normal WBC count. ${ }^{50-52}$ Thrombocytopenia in the setting of influenza infection has been noted in a number of case reports, often in the setting of concomitant antibiotic therapy, which can also affect the platelet (PLT) count. ${ }^{50,52,53}$ Although influenza does not appear to cause major hematologic perturbations in patients, it has been shown to interact with blood elements. ${ }^{54}$ Influenza has been shown to adsorb to PLTs and
RBC with equal kinetics and to elute from PLTs more slowly and less completely than from RBCs. ${ }^{55}$ Binding of live or dead influenza virus to PLTs in vitro caused morphologic signs of damage to the PLTs including swelling, ballooning, and fragmentation, with a pronounced decrease in PLT counts. ${ }^{56}$ Intravenous infusion of influenza virus in rabbits caused transient thrombocytopenia to levels 50 percent of normal for 1 to 2 days' duration. In vitro experiments have shown that anti-hemagglutinin antibody causes lysis of influenza-treated PLTs via the classical complement pathway in the presence of autologous human serum. ${ }^{57}$ Although hematologic abnormalities aside from lymphopenia are not typically observed during the course of influenza infection, the available data suggest that influenza can interact with WBCs, RBCs and PLTs. If viremia occurred primarily in presymptomatic or asymptomatic infection, transient disturbances of hematocrit or PLT counts would likely escape detection. Binding to cellular components within the blood in theory could facilitate influenza viremia, although evidence for the phenomenon is lacking in humans.

\section{ANIMAL MODELS OF INFLUENZA INFECTION AND VIREMIA}

Animal models may provide insight into the frequency of viremia after influenza infection, and the murine model of influenza infection has been used as a prototypic model of an antiviral immune response, defining which subsets of immune cells are important in protection from lethal lytic virus infection. Although the model has been widely used for study of the immune response to viruses ${ }^{58}$ relatively few studies measure influenza viremia as a study outcome. In mice infected with influenza intravenously, viremia persists for approximately 1 week in immunocompetent mice and shows rising titers at 1 week in gamma-irradiated mice. ${ }^{59}$ In mice intranasally infected with influenza, virus could be detected in RBC fractions on Days 1 through 5 but not in PBMNCs or plasma aliquots. ${ }^{60}$ Virus disseminated widely to a number of organs, and viremia was blocked by treatment of mice with hyperimmune serum before infection. Local lung damage may play a role in the development of viremia. After intranasal influenza infection, no mice with histologically normal lungs developed detectable viremia, whereas 9 of 20 mice with lung congestion had influenza RNA detected in blood by RT-PCR ${ }^{61}$ Although the murine model has been widely used to study influenza infection, pathogenicity of influenza isolates in mice and men does not always show a correlation. ${ }^{62}$ Simian models of influenza infection generally reflect lower pathogenicity than in humans, ${ }^{63,64}$ and cynomolgus macaques show less systemic dissemination of highly pathogenic avian influenza virus than human hosts. ${ }^{65} \mathrm{~A}$ model animal that may more closely parallel human influenza infection is the ferret. Human influenza 

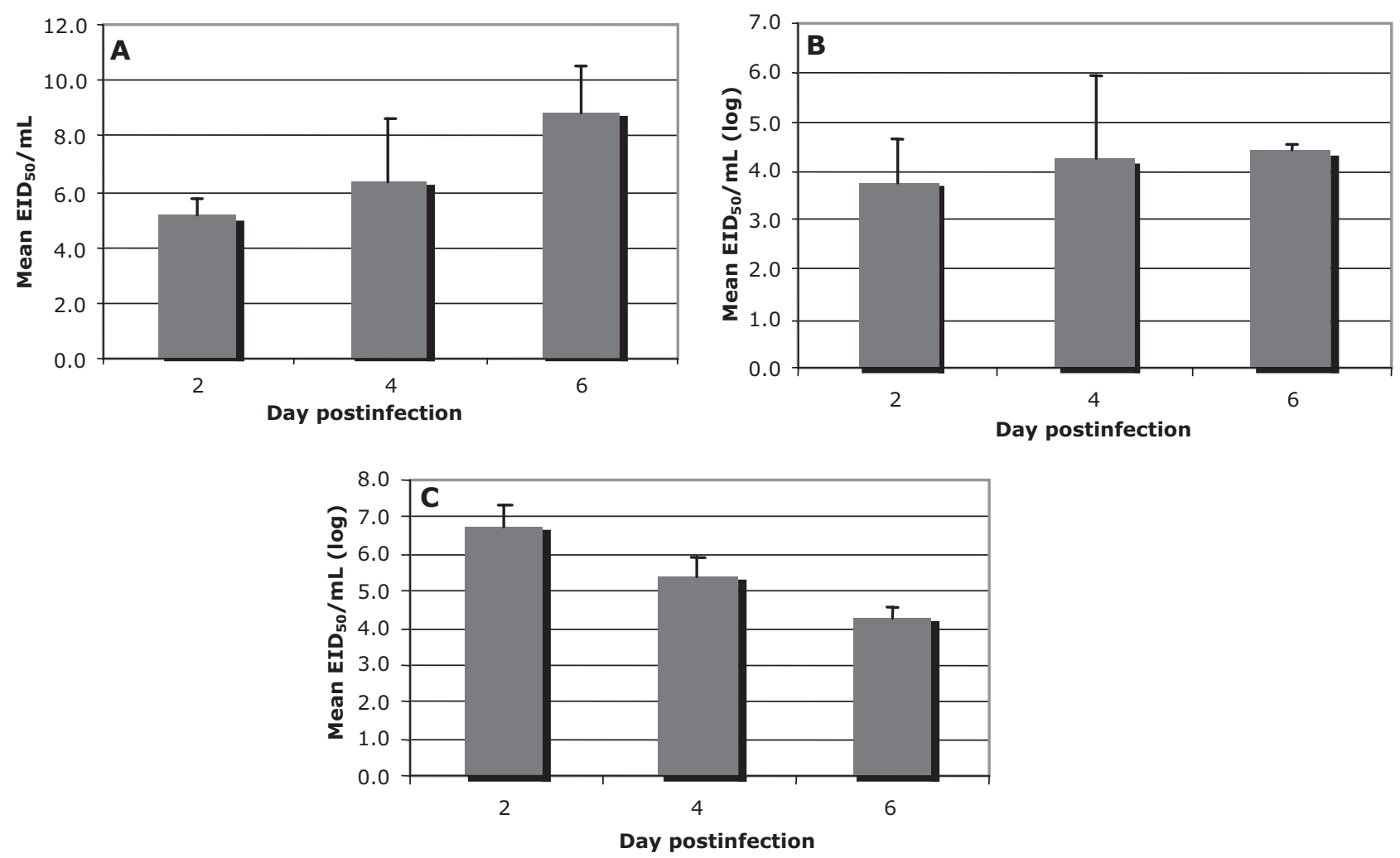

Fig. 2. Dissemination of H5N1 influenza A in ferrets. Viral loads in nasal turbinate (A), lung (B), and spleen (C) tissue from nine intranasally H5N1 (A/Vietnam/1203/2004) influenza A-infected ferrets. Ferrets were euthanized on Days 2, 4, and 6 postinfection, and tissues were immediately snap-frozen, homogenized, and inoculated onto embryonated hen's eggs for 50 percent egg infectious dose $\left(\mathrm{EID}_{50}\right)$ determination to assess viral load in the specified tissues. ${ }^{83}$ Data shown represent the mean viral load in tissues from three ferrets per time point.

A strains with differential pathogenicity showed similar differential pathogenicity in ferrets, yet caused nonpathogenic infection in mice, ${ }^{66}$ although ferrets may be more susceptible to influenza than humans. ${ }^{67}$ Ferrets appear to be susceptible to highly pathogenic avian influenza H5N1 virus, developing severe symptoms with isolates from both fatal and mild human cases. ${ }^{68}$ Multiple organ involvement is also observed in the ferret model of highly pathogenic avian influenza H5N1 infection. Representative original data from ferret challenge experiments with H5N1 influenza virus are included, revealing widespread productive viral replication in the brain, spleen, and upper and lower respiratory tract (Fig. 2). Ferret experiments were performed at the Southern Research Institute (Birmingham, AL) and were supported by the Canadian Institutes of Health Research.

\section{HIGHLY PATHOGENIC AVIAN INFLUENZA A (H5N1)}

\section{Characteristics of transmission}

Highly pathogenic avian influenza A (H5N1) has infected bird flocks in an almost worldwide distribution, yet transmission to humans remains rare, and human-tohuman transmission has only occurred in isolated cases. $^{69,70}$ Tropism of the hemagglutinin molecule for its sialic acid receptor may influence the ease of infection and subsequent transmission of this avian influenza virus in humans. Avian influenza hemagglutinin binds to sialic acid linked to galactose by an $\alpha 2,3$ linkage (SA $\alpha 2,3 \mathrm{Gal}$ ), whereas human influenza hemagglutinin favors a sialic acid-galactose $\alpha 2,6$ linkage (SA $\alpha 2,6 \mathrm{Gal}){ }^{71,72}$ Upper airway epithelial cells in humans contain predominantly SA 2 2,6Gal, whereas SA 2 2,3Gal can be found in bronchiolar and alveolar cells. ${ }^{73}$ Although clinical infection of humans with $\mathrm{H} 5 \mathrm{~N} 1$ virus rarely occurs, up to 10 percent of poultry workers in Hong Kong developed antibody responses to $\mathrm{H} 5$, implying that subclinical or abortive infection might occur in highly exposed subjects. ${ }^{74}$ Exposure to live poultry was the only significant risk factor for transmission of H5N1 disease recognized in the 1997 Hong Kong H5N1 outbreak..$^{75}$ Mutations allowing use of the SA $2,6 \mathrm{Gal}$ receptor would likely be needed, in addition to other genetic changes, to transform the currently circulating avian H5N1 influenza virus into a humantropic strain. 


\section{Disease manifestations in humans}

Avian influenza H5N1 infection in humans causes increased morbidity and mortality compared to seasonal influenza infections in reported cases. H5N1 influenza infection in humans manifests as lower respiratory tract disease, consistent with the expression pattern of receptors for the virus. ${ }^{2,70,76,77}$ Initial symptoms are similar to typical influenzalike illness, with fever (usually $>38^{\circ} \mathrm{C}$ ), cough, and dyspnea common. ${ }^{2,77}$ Gastrointestinal symptoms also appear prominent in many case series, with one documented subject presenting with diarrhea but no initial respiratory symptoms. ${ }^{78}$ An outbreak of H7N7 avian influenza was notable for conjunctivitis as a presenting symptom $^{28}$ although this has not been noted in $\mathrm{H} 5 \mathrm{N1}$ influenza illness. Although initial symptoms predominantly involve the respiratory system, multiple extrapulmonary tissues are affected by $\mathrm{H} 5 \mathrm{N1}$ avian influenza, including the gastrointestinal tract and prominent involvement of the liver and kidneys., ${ }^{2,76,77}$ Encephalitis with virus isolated from the CSF has been reported in a child with no early pulmonary involvement. ${ }^{78}$ Hematologic abnormalities are also prominent, with lymphopenia and thrombocytopenia frequently reported ${ }^{2,76}$ and pancytopenia noted in one case series. ${ }^{77}$ Marrow studies reveal hypoplastic marrow with a reactive hemophagocytic syndrome. ${ }^{76}$ The involvement of multiple organ systems in H5N1 highly pathogenic avian influenza infection in humans suggests that subjects might show evidence of viremia. In fact, in two published studies measuring virus in the plasma or serum, virus was isolated, in the first case on Day 10 of illness (viral load not reported), and in the second a viral load of 85,000 RNA copies per mL was detected. ${ }^{78,79}$ More recently, de Jong and coworkers ${ }^{80}$ reported finding $\mathrm{H} 5 \mathrm{~N} 1$ viral RNA in the blood of 9 of 16 Vietnamese patients infected with avian influenza. These results suggest that viremia can occur at reasonably high levels and for prolonged periods in people with symptomatic H5N1 influenza infection. Based on limited data, it appears that symptomatic H5N1 influenza infection and infection with other new pandemic strains in humans may be more likely than currently circulating influenza A strains to result in viremia. ${ }^{78,80}$ The risk of viremia during the incubation period of $\mathrm{H} 5 \mathrm{~N} 1$ infection or asymptomatic infection with other influenza A viruses novel to humans is unknown.

\section{SIGNIFICANCE AND SUMMARY}

With the advent of routine testing for multiple pathogens, the US blood supply has become increasingly safe. Many adverse events associated with transfusion are not related to transfusion-transmitted diseases, but rather immunologic effects (transfusion-related acute lung injury, ABO mismatch) or hemodynamic effects (transfusionassociated circulatory overload). Furthermore, the blood banks and test manufacturers have demonstrated that they can rapidly respond to interdict newly introduced infectious agents, as was seen in the response to West Nile virus introduction to the US. ${ }^{81}$ Not all pathogens that infect blood donors, however, are successfully screened, with unknown impact on recipients. One potentially unrecognized pathogen in the blood supply is influenza virus. The incidence of viremia in blood donors is thought to be low, particularly for seasonal influenza, but has not been adequately studied. Older studies of influenza A experimental infection and one report of a naturally infected person suggest that viremia can occur before symptom onset. Even if influenza viremia occurs, the incidence is likely low during seasonal influenza outbreaks and would not pose a large risk to the safety of the blood supply.

Research projects are ongoing to address whether virus can be detected in blood collected during periods of transmission within the community. As part of the Retrovirus Epidemiology Donor Study II (REDS II), we are examining the incidence of influenza viremia in a retrospective cohort of blood donors, the REDS Allogeneic Donor and Recipient (RADAR) repository. The RADAR repository contains more than 120,000 whole-blood and plasma specimens that are linked to donor zip code and date of blood donation, but delinked from personal donor identifiers. Access to the repository will allow identification of samples collected during periods of widespread influenza activity in the community. Detection of influenza in the blood presents a challenge due to the lower viral loads found in blood compared to nasopharyngeal secretions. RBC or PLT fractions may contain more influenza than plasma or WBC fractions due to interaction with the hemagglutinin moiety of influenza. ${ }^{57}$ We will first determine the blood fraction that contains the highest level of virus. Once the appropriate blood fractions are identified, samples from RADAR repository obtained during periods of known epidemic influenza A outbreak, and samples obtained during periods of very low influenza activity will be tested for the presence of influenza A RNA. This ongoing project will quantify the risk of occult influenza viremia in blood donors during periods of high-level transmission of influenza in the community. If viremia is detected then the issue of iatrogenic transmission of influenza by transfusion will need to be reassessed. In addition, further studies of people ill with seasonal and avian $\mathrm{H} 5 \mathrm{~N} 1$ virus infection are needed to evaluate the presence of viremia both by nucleic acid amplification and viral culture in comparison to viral isolates obtained from the respiratory tract to understand possible strain-specific and genetic features of viruses isolated from both sites.

Because pandemic influenza might be more likely to cause viremia and have higher pathogenicity than seasonal influenza, the risk of viremia during circulation of a new pandemic strain of influenza is more worrisome than 
for possible transfusion-associated infection with currently circulating influenza, particularly given high rates in the population of antibody to current strains. More data is clearly needed to understand strain-specific characteristics that may predispose to viremia in infected persons. Based on limited available data, it appears that H5N1 virus infection and infection with newly circulating pandemic viruses in humans may be more likely than circulating seasonal human influenza viruses to cause a viremic phase. It is unclear how often asymptomatic infection occurs in avian influenza, although this may also be strain-specific as studies of human infection with earlier H5N1 strains found more mild or asymptomatic infections than studies of more recent H5N1 strains. ${ }^{74,82}$ If and when a new pandemic appears, and the causative strain becomes evident, assuring the safety of the blood supply through study of donor viremia would be an important step. Widespread illness associated with an influenza pandemic among both donors and blood bank staff would stretch the ability of blood banks to provide a safe and adequate blood supply, and broad and indiscriminate screening based on exposure would only worsen potential product shortages. As part of pandemic planning, the resources to rapidly evaluate and implement screening measures for influenza viremia should be developed, allowing a rapid response to this potential threat to blood safety and availability.

\section{ACKNOWLEDGMENT}

The authors thank Carolyn Bridges, MD, for her review of the manuscript.

\section{REFERENCES}

1. Yu H, Shu Y, Hu S, et al. The first confirmed human case of avian influenza A (H5N1) in Mainland China. Lancet 2006; $367: 84$.

2. Tran TH, Nguyen TL, Nguyen TD, et al. Avian influenza A (H5N1) in 10 patients in Vietnam. N Engl J Med 2004;350: 1179-88.

3. Outbreak news. Avian influenza, Azerbaijan. Wkly Epidemiol Rec 2006;81:105-6.

4. Outbreak news. Avian influenza, Turkey. Wkly Epidemiol Rec 2006;81:13-5.

5. Englund JA, Champlin RE, Wyde PR, et al. Common emergence of amantadine- and rimantadine-resistant influenza A viruses in symptomatic immunocompromised adults. Clin Infect Dis, 1998;26:1418-24.

6. Raboni SM, Nogueira MB, Tsuchiya LR, et al. Respiratory tract viral infections in bone marrow transplant patients. Transplantation 2003;76:142-6.

7. 2004-2005 U.S. influenza season summary. Atlanta (GA): Centers for Disease Control and Prevention; 2005.
8. Thompson WW, Shay DK, Weintraub E, et al. Mortality associated with influenza and respiratory syncytial virus in the United States. JAMA 2003;289:179-86.

9. Smith NM, Bresee JS, Shay DK, et al. Prevention and Control of Influenza: recommendations of the Advisory Committee on Immunization Practices (ACIP). MMWR Recomm Rep 2006;55:1-42.

10. Bueving HJ, van der Wouden JC, Berger MY, Thomas S. Incidence of influenza and associated illness in children aged 0-19 years: a systematic review. Rev Med Virol 2005; 15:383-91.

11. Glezen WP, Couch RB. Interpandemic influenza in the Houston area, 1974-76. N Engl J Med 1978;298:587-92.

12. Heikkinen $\mathrm{T}$, Ziegler $\mathrm{T}$, Peltola V, et al. Incidence of influenza in Finnish children. Pediatr Infect Dis J 2003;22: S204-6.

13. Fox JP, Hall CE, Cooney MK, Foy HM. Influenza virus infections in Seattle families, 1975-1979. I. Study design, methods and the occurrence of infections by time and age. Am J Epidemiol 1982;116:212-27.

14. Monto AS, Koopman JS, Longini IM Jr. Tecumseh study of illness. XIII. Influenza infection and disease, 1976-1981. Am J Epidemiol 1985;121:811-22.

15. Earhart KC, Beadle C, Miller LK, et al. Outbreak of influenza in highly vaccinated crew of U.S. Navy ship. Emerg Infect Dis 2001;7:463-5.

16. Glezen WP. Emerging infections: pandemic influenza. Epidemiol Rev 1996;18:64-76.

17. Woodall J, Rowson KE, McDonald JC. Age and Asian influenza, 1957. Br Med J 1958;2:1316-8.

18. Miller DL, Reid D, Diamond JR, et al. Hong Kong influenza in the Royal Air force 1968-70. J Hyg 1973;71:535-47.

19. Colman PM, Varghese JN, Laver WG. Structure of the catalytic and antigenic sites in influenza virus neuraminidase. Nature 1983;303:41-4.

20. Potter CW, Oxford JS. Determinants of immunity to influenza infection in man. Br Med Bull 1979;35:69-75.

21. Monto AS, Kendal AP. Effect of neuraminidase antibody on Hong Kong influenza. Lancet 1973;1:623-5.

22. Wiley DC, Wilson IA, Skehel JJ. Structural identification of the antibody-binding sites of Hong Kong influenza haemagglutinin and their involvement in antigenic variation. Nature 1981;289:373-8.

23. Hirst GK, Gotlieb T. The experimental production of combination forms of virus. I. Occurrence of combination forms after simultaneous inoculation of the allantoic sac with two distinct strains of influenza virus. J Exp Med 1953; 98:41-52.

24. Fouchier RA, Munster V, Wallensten A, et al. Characterization of a novel influenza A virus hemagglutinin subtype (H16) obtained from black-headed gulls. J Virol 2005;79: 2814-22.

25. Tumpey TM, Basler CF, Aguilar PV, et al. Characterization of the reconstructed 1918 Spanish influenza pandemic virus. Science 2005;310:77-80. 
26. de Jong JC, Claas EC, Osterhaus AD, Webster RG, Lim WL. A pandemic warning? Nature 1997;389:554.

27. Peiris M, Yuen KY, Leung CW, et al. Human infection with influenza H9N2. Lancet 1999;354:916-7.

28. Fouchier RA, Schneeberger PM, Rozendaal FW, et al. Avian influenza A virus (H7N7) associated with human conjunctivitis and a fatal case of acute respiratory distress syndrome. Proc Natl Acad Sci U S A 2004;101: 1356-61.

29. Tweed SA, Skowronski DM, David ST, et al. Human illness from avian influenza H7N3, British Columbia. Emerg Infect Dis 2004;10:2196-9.

30. Naficy K. Human influenza infection with proved viremia: report of a case. N Engl J Med 1963;269:964-6.

31. Oseasohn R, Adelson L, Kaji M. Clinicopathologic study of thirty-three fatal cases of Asian influenza. N Engl J Med 1959;260:509-18.

32. Khakpour M, Saidi A, Naficy K. Proved viraemia in Asian influenza (Hong Kong variant) during incubation period. Br Med J 1969;4:208-9.

33. Minuse E, Willis PW 3rd, Davenport FM, Francis T Jr. An attempt to demonstrate viremia in cases of Asian influenza. J Lab Clin Med 1962;59:1016-9.

34. Poliakova TG, Ketiladze ES, Zhilina NN, Stakhanova VM. [Viremia in influenza A2 (Hong Kong)]. Vopr Virusol 1970; 15:724-8.

35. Lehmann NI, Gust ID. Viraemia in influenza: a report of two cases. Med J Aust 1971;2:1166-9.

36. Roberts GT, Roberts JT. Postsplenectomy sepsis due to influenzal viremia and pneumococcemia. Can Med Assoc J 1976;115:435-7.

37. Tsuruoka H, Xu H, Kuroda K, et al. Detection of influenza virus RNA in peripheral blood mononuclear cells of influenza patients. Jpn J Med Sci Biol 1997;50:27-34.

38. Update: influenza activity-United States and worldwide, 1993. MMWR Morb Mortal Wkly Rep 1993;42:752-5.

39. Xu H, Yasui O, Tsuruoka H, et al. Isolation of Type B influenza virus from the blood of children. Clin Infect Dis 1998; 27:654-5.

40. Stanley ED, Jackson GG. Viremia in Asian influenza. Trans Assoc Am Phys 1966;79:376-87.

41. Mori I, Nagafuji H, Matsumoto K, Kimura Y. Use of the polymerase chain reaction for demonstration of influenza virus dissemination in children. Clin Infect Dis 1997;24: 736-7.

42. Kawada J, Kimura H, Ito Y, et al. Systemic cytokine responses in patients with influenza-associated encephalopathy. J Infect Dis 2003;188:690-8.

43. Yawn DH, Pyeatte JC, Joseph JM, Eichler SL, Garcia-Bunuel R. Transplacental transfer of influenza virus. JAMA 1971; 216:1022-3.

44. McGregor JA, Burns JC, Levin ML, Burlington B, Meiklejohn G. Transplacental passage of influenza A/Bangkok (H3N2) mimicking amniotic fluid infection syndrome. Am J Obstet Gynecol 1984;149:856-9.
45. Kaji M, Oseasohn R, Jordan WS Jr, Dingle JH. Isolation of Asian virus from extrapulmonary tissues in fatal human influenza. Proc Soc Exp Biol Med 1959;100:272-5.

46. Ito $\mathrm{Y}$, Ichiyama $\mathrm{T}$, Kimura $\mathrm{H}$, et al. Detection of influenza virus RNA by reverse transcription-PCR and proinflammatory cytokines in influenza-virus-associated encephalopathy. J Med Virol 1999;58:420-5.

47. Sugaya N, Yoshikawa T, Miura M, et al. Influenza encephalopathy associated with infection with human herpesvirus 6 and/or human herpesvirus 7. Clin Infect Dis 2002;34: 461-6.

48. Ray CG, Icenogle TB, Minnich LL, Copeland JG, Grogan TM. The use of intravenous ribavirin to treat influenza virus-associated acute myocarditis. J Infect Dis 1989;159: 829-36.

49. Alford RH, Kasel JA, Gerone PJ, Knight V. Human influenza resulting from aerosol inhalation. Proc Soc Exp Biol Med 1966;122:800-4.

50. Chang LY, Huang FY, Wu YC, et al. Childhood severe acute respiratory syndrome in Taiwan and how to differentiate it from childhood influenza infection. Arch Pediatr Adolesc Med 2004;158:1037-42.

51. Lupovitch A. White cell differential count and influenza A. Am J Med 2005;118:1306-7; author reply 1307-9.

52. Rice J, Resar LM. Hematologic abnormalities associated with influenza A infection. a report of 3 cases. Am J Med Sci 1998;316:401-3.

53. Karalakulasingam R, Schacht RA, Lansing AM, Raff MJ. Influenza virus pneumonia after renal transplant. Postgrad Med 1977;62:164-7.

54. Buzzell A, Hanig M. The mechanism of hemagglutination by influenza virus. Adv Virus Res 1958;5:289-346.

55. Jerushalmy Z, Kohn A, De Vries A. Interaction of myxoviruses with human blood platelets in vitro. Proc Soc Exp Biol Med 1961;106:462-6.

56. Terada H, Baldini M, Ebbe S, Madoff MA. Interaction of influenza virus with blood platelets. Blood 1966;28:213-28.

57. Kazatchkine MD, Lambre CR, Kieffer N, Maillet F, Nurden AT. Membrane-bound hemagglutinin mediates antibody and complement-dependent lysis of influenza virustreated human platelets in autologous serum. J Clin Invest 1984;74:976-84.

58. Graham MB, Braciale TJ. Resistance to and recovery from lethal influenza virus infection in B lymphocyte-deficient mice. J Exp Med 1997;186:2063-8.

59. Tsuru S, Fujisawa H, Taniguchi M, Zinnaka Y, Nomoto K. Mechanism of protection during the early phase of a generalized viral infection. II. Contribution of polymorphonuclear leukocytes to protection against intravenous infection with influenza virus. J Gen Virol 1987;68:419-24.

60. Mori I, Komatsu T, Takeuchi K, et al. Viremia induced by influenza virus. Microb Pathog 1995;19:237-44.

61. Davis LE, Kornfeld M, Daniels RS, Skehel JJ. Experimental influenza causes a non-permissive viral infection of brain, liver and muscle. J Neurovirol 2000;6:529-36. 
62. Katz JM, Lu X, Tumpey TM, et al. Molecular correlates of influenza A H5N1 virus pathogenesis in mice. J Virol 2000; 74:10807-10.

63. Murphy BR, Hinshaw VS, Sly DL, et al. Virulence of avian influenza A viruses for squirrel monkeys. Infect Immun 1982;37:1119-26.

64. Murphy BR, Sly DL, Hosier NT, London WT, Chanock RM. Evaluation of three strains of influenza A virus in humans and in owl, cebus, and squirrel monkeys. Infect Immun 1980;28:688-91.

65. Rimmelzwaan GF, Kuiken T, van Amerongen G, et al. Pathogenesis of influenza A (H5N1) virus infection in a primate model. J Virol 2001;75:6687-91.

66. Toms GL, Bird RA, Kingsman SM, Sweet C, Smith H. The behaviour in ferrets of two closely related clones of influenza virus of differing virulence for man. Br J Exp Pathol 1976;57:37-48.

67. Campbell D, Sweet C, Smith H. Comparisons of virulence of influenza virus recombinants in ferrets in relation to their behaviour in man and their genetic constitution. J Gen Virol 1979;44:37-44.

68. Zitzow LA, Rowe T, Morken T, et al. Pathogenesis of avian influenza A (H5N1) viruses in ferrets. J Virol 2002;76: 4420-9.

69. Outbreak news. Avian influenza, Indonesia—update. Wkly Epidemiol Rec 2006;81:233.

70. Ungchusak K, Auewarakul P, Dowell SF, et al. Probable person-to-person transmission of avian influenza A (H5N1). N Engl J Med 2005;352:333-40.

71. Ito T, Suzuki Y, Takada A, et al. Differences in sialic acidgalactose linkages in the chicken egg amnion and allantois influence human influenza virus receptor specificity and variant selection. J Virol 1997;71:3357-62.

72. Matrosovich MN, Gambaryan AS, Teneberg S, et al. Avian influenza A viruses differ from human viruses by recognition of sialyloligosaccharides and gangliosides and by a higher conservation of the HA receptor-binding site. Virology 1997;233:224-34.

73. Shinya K, Ebina M, Yamada S, et al. Avian flu: influenza virus receptors in the human airway. Nature 2006;440: 435-6.

74. Bridges CB, Lim W, Hu-Primmer J, et al. Risk of influenza A (H5N1) infection among poultry workers, Hong Kong, 1997-1998. J Infect Dis 2002;185:1005-10.

75. Mounts AW, Kwong H, Izurieta HS, et al. Case-control study of risk factors for avian influenza A (H5N1) disease, Hong Kong, 1997. J Infect Dis 1999;180:505-8.

76. To KF, Chan PK, Chan KF, et al. Pathology of fatal human infection associated with avian influenza A H5N1 virus. J Med Virol 2001;63:242-6.

77. Yuen KY, Chan PK, Peiris M, et al. Clinical features and rapid viral diagnosis of human disease associated with avian influenza A H5N1 virus. Lancet 1998;351: 467-71.

78. de Jong MD, Bach VC, Phan TQ, et al. Fatal avian influenza A (H5N1) in a child presenting with diarrhea followed by coma. N Engl J Med 2005;352:686-91.

79. Chutinimitkul S, Bhattarakosol P, Srisuratanon S, et al. H5N1 influenza A virus and infected human plasma. Emerg Infect Dis 2006;12:1041-3.

80. de Jong MD, Simmons CP, Thanh TT, et al. Fatal outcome of human influenza A (H5N1) is associated with high viral load and hypercytokinemia. Nat Med 2006;12:1203-7.

81. Update: West Nile virus screening of blood donations and transfusion-associated transmission-United States, 2003. MMWR Morb Mortal Wkly Rep 2004;53:281-4.

82. Apisarnthanarak A, Erb S, Stephenson I, et al. Seroprevalence of anti-H5 antibody among Thai health care workers after exposure to avian influenza (H5N1) in a tertiary care center. Clin Infect Dis 2005 2005;40:e16-8.

83. Reed LJ, Muench H. A simple method for estimating fifty percent endpoints. Am J Hygiene 1938;27:493-7. 